\title{
UNIVERSIDADE, COMUNIDADE E CONHECIMENTOS: INTERAÇÕES NECESSÁRIAS À FORMAÇÃO PEDÁGÓGICA
}

\author{
UNIVERSITY, COMMUNITY AND KNOWLEDGE: \\ INTERACTIONS NECESSARY FOR PEDAGOGICAL TRAINING
}

\author{
UNIVERSIDAD, COMUNIDAD Y CONOCIMIENTO: \\ INTERACCIONES NECESARIAS PARA \\ LA FORMACIÓN PEDAGÓGICA
}

Raimundo Nonato de Oliveira Falabelo ${ }^{\mathrm{I}}$

\begin{abstract}
Resumo Este trabalho apresenta resultados do Projeto de Pesquisa e Extensão Universitária, "Vidas em Aberto", realizado, desde 2005, com crianças em dificuldades na apropriação qualitativa da leitura e da escrita, moradoras do entorno do Campus Universitário de Cametá/UFPA. Metodologia: bolsistas de iniciação científica e extensionistas, do curso de Pedagogia, em vivência teórico-empírica, visitam famílias convidando suas crianças; os encontros acontecem no campus aos finais de semana; as atividades didáticas e culturais fazem uso de textos narrativos e poéticos; desenho, pintura; música regional/local; lendas, mitos, folclore, enquanto recursos indispensáveis à apropriação e ao domínio da linguagem. Trabalhar a leitura e a escrita de forma rica e diversificada, possibilitando a interação com os diversos gêneros simbólicos, vem se constituindo em motivadora estratégia a essas crianças ressignificar suas relações com os conhecimentos escolares e a cultura historicamente acumulada pela humanidade, experimentando a leitura e a escrita como atividades e práticas sociais fundamentais a sua formação.
\end{abstract}

Palavras-chave: Criança; Leitura; Escrita; Inclusão Social.

Abstract This paper presents results of the University Extension Project, "Lives in Open" held since 2005, with children in difficulties in qualitative appropriation of reading and writing, the surrounding residents of University Campus Cametá/UFPA. Methodology: ex-

Universidade Federal do Pará (UFPA), Belém/PA - Brasil. 
tension scholars, the Faculty of Education in theoretical and empirical experience, visiting families inviting their children. The meetings are held on the campus on weekends; the educational and cultural activities make use of narrative and poetic texts; drawing, painting; regional music / site; myths, folklore, while resources required to appropriation and mastery of language. Work reading and writing rich and diversified manner, enabling the interaction with various symbolic genres, are becoming an motivating strategy for these children reframe its relationship with the school knowledge and historically accumulated culture for humanity, experiencing reading and written as activities and basic social practices their formation.

KeY-Words: Child; ReAding; Writing; Social InCLUSION.

Resumen Este artículo presenta los resultados del Proyecto de Extensión de la Universidad, "Vives en aberto", realizado desde el año 2005, con los niños en dificultades en la apropiación cualitativa de la lectura y la escritura, los habitantes de los alrededores de la Universidad Campus Cametá/UFPA. Metodología: compañeros de extensión, el curso de Pedagogía en la experiencia teórica y empírica, visitando familias invitando a sus hijos; las reuniones se llevan a cabo en el campus los fines de semana; las actividades educativas y culturales hacen uso de textos narrativos y poéticos; dibujo, pintura; música / sitio regional; leyendas, mitos, folklore, mientras que los recursos indispensables para la apropiación y dominio de la lengua. Trabajar la lectura y escritura de forma rica y diversificada, lo que permite la interacción con varios géneros simbólicos, se están convirtiendo en una estrategia de motivación para estos niños replantear su relación con el conocimiento escolar y la cultura históricamente acumulada por la humanidad, experimentando la lectura y escrita como las actividades y prácticas sociales básicos de su formación.

Palabras Clave: Niños; lectura; escrito; La inclusión social.

\section{INTRODUÇÃo}

Este trabalho apresenta resultados do Projeto de Pesquisa e Extensão Universitária, "Vidas em Aberto", 1 que vem sendo realizado, desde 2005, com crianças em dificuldades na apropriação qualitativa da leitura e da escrita, por bolsistas extensionistas e de iniciação científica do Curso de Licenciatura em Pedagogia/UFPA. ${ }^{2}$

1 A Universidade Federal do Pará apresenta uma estrutura multicampi, com sede na capital do Estado do Pará, Belém, e diversos campi espalhados pelo interior. Esse trabalho é desenvolvimento no Campus Universitário de Cametá, cidade polo que atende a outros municípios em seu entorno. O Projeto, assim, atende a crianças que vivem nas proximidades do referido campus, localizado no Bairro da Matinha.

2 Vidas em Aberto: Muitas crianças, das camadas empobrecidas da sociedade, por motivos diversos, têm relações de encantos passageiros e longos desencantos com a escola; reprovações, repetências contínuas, evasões, frágeis retornos à escola marcam suas experiências como estudantes; vidas com um não-destino volatilmente em aberto; ao contrário, outras crianças, parece, vivem relações mais duradouras de encantos com a escola e com a aprendizagem. Esse duplo olhar, porém brevemente simplificado aqui, deu nome ao Projeto de Extensão e Pesquisa que tem por objetivo ir ao encontro dessas crianças, por assim dizer, com seus irregulares percursos na vivência escolar. Algumas parecem ter um destino (vida) mais linearmente 
Sucintamente, explicita-se que o referido Projeto tem como temática a questão da interação afetividade/emoções, intelecto/cognição e conhecimentos escolares. O lócus empírico é o chão da sala de aula, investigando-se concepções teóricas e práticas de alfabetização e letramento, atitudes, comportamentos emocionais e afetivos, dizeres e fazeres de professores e crianças.

O que tem chamado a atenção na pesquisa, é perceber-se que a teoria da carência cultural (PATTO, 1993) ainda se faz presente nos dizeres de professores quando tentam justificar o insucesso de crianças na apropriação da leitura e da escrita. Essas crianças, principalmente pertencentes às classes sociais populares, são vistas, por seus sucessivos fracassos, como carentes, principalmente carentes afetivos, sujeitos portadores de baixa autoestima e que necessitariam da paciência, da tolerância, de carinho e afagos de seus professores (FALABELO; LEÃO, 2014).

Brevemente, pode-se dizer, segundo Patto (1993), que ao tentar explicar o desigual desenvolvimento escolar entre crianças, essa teoria fundamenta-se em preconceitos e estereótipos, imputando às classes subalternas atitudes agressivas, desinteresse, preguiça, vícios, carência afetiva.

Nas ações de intercambiamento da pesquisa com a extensão, longe dessa ideia de "afetividade", citada, defende-se o pressuposto de que as relações de carinho (afeto) não podem fazer-se desvinculadas das relações com os conhecimentos escolares significativos, das relações com os conteúdos da aprendizagem que os desafiem, dando-lhes a percepção de que, realmente, estão aprendendo. O afetivo, assim, se apresentaria, não como uma dimensão exterior a sobrepor-se aos conhecimentos escolares, mas como uma dimensão constitutiva e constituinte de uma articulação triádica professor - conhecimentos - alunos (FALABELO, 2005).

Dessa forma, o grupo social - a sociedade, a escola, a Universidade - tem responsabilidade fundamental no desenvolvimento e formação dessas crianças. Ou seja, cabe ao grupo social prover, de forma rica e qualitativa, as oportunidades de aprendizagem, de apropriação dos conhecimentos científicos e culturais; compete, portanto, a responsabilidade de instaurar ações didáticas, pedagógicas, diversificadas atividades simbólicas, culturais, para que as crianças experimentem o processo de alfabetização - aquisição da leitura e escrita enquanto prática social e cultural.

No desenvolvimento das atividades, assumiu-se o pressuposto de criar em ambientes escolares e não escolares, a relação dessas crianças com os diversos gêneros simbólicos, de forma que viessem a ressignificar as suas relações com os saberes, os conhecimentos e a cultura historicamente acumulada pela humanidade, experimentando a leitura e a escrita como atividades sociais fundamentais à sua formação.

organizado e que comportaria certa previsibilidade em sua trajetória escolar; outras parecem escapar, minimamente, a essa previsibilidade linear das sucessivas etapas do aprender; suas vidas, sempre em aberto, por rotineiros desencantos, esperados abandonos, reprovações, escapam à normatividade e à racional previsibilidade contidas nos atos de aprender e ser bem-sucedido na escola. 
Assumindo-se como orientação teórica (VIGOTSKI, 2000a, 2000b, 2001), o fato de que somos sujeitos simbólicos, que nos constituímos nas relações sociais, mediadas pela linguagem e pela cultura, ações formativas, portanto, destinadas a essas crianças, devem centrar-se no envolvimento rico e diversificado dos mesmos com o conhecimento, de forma significativa.

As atividades didáticas, pedagógicas e culturais realizam-se em escola da comunidade ou na própria universidade, que conta com um ambiente apropriado. Nos encontros, as crianças participam de oficinas para a prática da leitura e da escrita, utilizando-se diversificados e diferenciados suportes metodológicos. Crianças, assim, em seu processo de formação, precisam do apoio dos distintos e diferentes grupos sociais, entre eles, a Universidade, para que possam reescrever e escrever suas biografias em condições de produção que lhes garantam o desenvolvimento integral de seu psiquismo, isto é, suas funções intelectuais, emocionais e socioafetivas.

Os eventos pedagógicos, de formação e de interação das crianças com os conhecimentos, são, igualmente, eventos de pesquisa e reflexões teóricas e metodológicas. Ressalte-se, ainda, a relevância de se aproximar o conhecimento acadêmico da realidade das práticas escolares, realizando-se, assim, o princípio da articulação entre conhecimentos acadêmicos, conhecimento/saberes/práticas dos professores e os saberes cotidianos das crianças (FALABELO, 2010, 2011). Realiza-se o objetivo, mencionado, ao promover-se a articulação teoria - prática, pela via da inserção de estudantes em ações de pesquisa e pedagógico-culturais.

\title{
A TEORIA MOTIVAdora: A CRIANÇA, LingUAGEM, CULTURA E DESENVOLVIMENTO HUMANO
}

\begin{abstract}
A atividade leitora apresenta, ao contrário, todos os traços de uma produção silenciosa: flutuação através da página, metamorfose do texto pelo olho que viaja, improvisação e expectação de significados induzidos de certas palavras, intersecções de espaços escritos, dança efêmera... Ele [o leitor] insinua as astúcias do prazer e de uma reapropriação no texto do outro: aí vai caçar, ali é transportado, ali se faz plural como os ruidos do corpo. Astúcia, metáfora, combinatória, esta produção é igualmente uma 'invenção'de memória. Faz das palavras as soluções de histórias mudas... Um mundo diferente (o do leitor) se introduz no lugar do autor.

- MICHEL DE CERTEAU, 1994
\end{abstract}

Para L. S. Vigotski (2000a), a leitura e a escrita não são elementos inatos à criança, sua aquisição depende das práticas sociais e culturais nas quais ela está inserida. A compreensão da leitura e da escrita não se dá de forma isolada, não é algo trazido em seus aspectos biológicos, mas construído em suas relações sociais, em sua relação com o outro/outros e com os conhecimentos. É, pois, uma troca de experiência que possibilita a aprendizagem e aquisição da escrita, o acesso ao mundo simbólico. 
Por exemplo, crianças que se julgam "burras" (ou assim são identificadas) - "Tia, não sei, tia, sô burra nisso" - por não ter domínio da leitura e escrita, parecem acreditar não poder vir a adquirir essas habilidades, o que afeta sua autoestima. O papel da escola é dar a essas crianças, num contexto sistemático, possibilidades para que elas possam se desenvolver, pois devemos olhar as crianças não apenas em suas dificuldades, mas "o que temos que buscar são as forças positivas [...], dirigindo-nos para alcançar o que é socialmente valorizado, construindo assim a autoestima perdida ou não estabelecida" (PADILHA, 1997, p. 33).

O que parece acontecer no contexto escolar é que só se consegue enxergar as dificuldades que as crianças apresentam no processo de aquisição da leitura e da escrita, sem se perguntar como ocorreu esse processo antes de sua entrada na escola, em que contexto social e cultural se encontravam e estão inseridas. É num mundo de leitores, ou num mundo em que a leitura e a escrita são pouco valorizadas? Em relação a essa situação, Vigotski (2000a, p. 130) chama a atenção para o fato de que "o aprendizado volta-se para as deficiências da criança, ao invés de voltar-se para os pontos fortes".

É necessário que o professor compreenda e aceite que seus alunos, ao entrarem na escola, trazem consigo uma história de vida, história essa constituída no seu meio sociocultural na sua sociedade de uma forma muito particular, o que vai marcar as diferenças entre as crianças em termos de conhecimentos e aprendizagens, ou de desenvolvimentos cognitivos, afetivos e emocionais, morais. O indivíduo internaliza formas de pensar, dizer e se comportar do seu cotidiano que pode não ser de interesse de outra pessoa, mas que deve ser respeitado, ou seja, precisamos levar em consideração os conceitos espontâneos da criança, ao ensinar os conceitos científicos, pois, segundo Vigotski (2000a, p. 135), “o desenvolvimento dos conceitos espontâneos da criança é ascendente, enquanto o desenvolvimento dos conceitos científicos é descendente".

Esses conceitos espontâneos são apropriados assistematicamente nas relações cotidianas, não sendo mediados por um processo explicativo de causalidade e relação, em que as palavras significam apenas um objeto ou uma ação percebida diretamente pela experiência de vida da criança. É a utilização sem intervenção das palavras ligada ao seu processo direto e aparente, sem uma tomada de consciência sobre esse processo, que Vigotski (2001) chama de pensamento espontâneo.

A criança relaciona a palavra com o conhecimento que tem, com suas experiências de vida, e isso precisa ser levado em consideração no ensino da leitura e da escrita, pois sabemos que a palavra não se desenvolve em nós naturalmente. É nas nossas relações com o outro que ela vai sendo incorporada, vai ganhando significados conscientes. As palavras desempenham um papel central não só no desenvolvimento do pensamento, mas também na evolução histórica da consciência como um todo (VIGOTSKI, 2000a).

O processo de construção do conhecimento pela criança é algo complexo e não reduzido. Não se deve cair na falsa crença de que o aprendizado de uma palavra ou de conteúdos seja o suficiente para a formação do indivíduo e, principalmente, para a aquisição da leitura e da escrita, pois aprender a ler, a escrever, é, antes de tudo, aprender a ler o mundo, compreender o seu contexto, não numa dominação mecânica de palavras, e sim numa rela- 
ção dinâmica que ligue linguagem e realidade. A palavra, pois, é a constituição da própria consciência, informa-nos Vigotski (2000a, 2000b, 2001). Ainda para o autor, a escrita tem grande significado para as crianças, despertando nelas necessidades próprias, pelo fato de se juntar a uma tarefa necessária e importante para a vida e, assim desenvolver-se em toda a sua complexidade sígnica.

Vigotski (2000a) faz ácida crítica à maneira formal e mecânica como é realizado o ensino da escrita:

\begin{abstract}
O ensino tem de ser organizado de forma que a leitura e a escrita se tornem necessárias às crianças. Se for usado apenas para escrever congratulações oficiais para membros da diretoria escolar ou para qualquer pessoa que o professor julgar interessante (e sugerir claramente para as crianças) então o exercício da escrita passará a ser puramente mecânico e logo poderá entediar as crianças, suas atividades não se expressarão em sua escrita e suas personalidades não desabrocharão. A leitura e a escrita devem ser algo de que a criança necessite (p. 155-156).
\end{abstract}

Em seu cotidiano, por estar inserida em uma sociedade letrada, semiótica, profundamente tecnologizada, a criança sente a necessidade da leitura e da escrita para tentar fazer algo que a ela é necessário. E ela busca o aprendizado de forma a realizar-se enquanto ser humano e constituir-se enquanto indivíduo. Ela vai ao encontro da escola com a expectativa de conseguir esse aprendizado, mas infelizmente, depara-se com algo muito diferente da sua realidade, pois, a leitura e a escrita são apresentadas de forma mecânica, vistas como uma obrigação e não de modo significativo, despertando o desejo de adquiri-la, o que acaba gerando o desinteresse, o fracasso e a evasão escolar. Essa é a grande crítica que Vigotski, na citação anterior, faz ao ensino da leitura e da escrita: um processo mecânico e desconectada da vida e do desenvolvimento de sua consciência.

A criança acaba sendo reprimida em seu desenvolvimento, impedida de desenvolver seu potencial, pois, não encontra, em seu percurso escolar, educadores mediadores, que os ajudem na descoberta e soluções das dificuldades de apropriação criativa da linguagem. A prática pedagógica centra-se na ideia de que quanto mais conteúdos forem repassados, tanto maior o desenvolvimento, esquecendo-se do principal: que a criança só aprende o que faz sentido para ela, só o que estiver de acordo com suas necessidades, pois, segundo Vigotski (2000a, p. 138), "os conceitos não ficam guardados na mente da criança como ervilhas em um saco, sem qualquer vínculo que os una".

Não se pode, em momento algum, cometer o erro de acreditar que todos os conceitos ensinados no contexto escolar serão assimilados pelos indivíduos, pois, se assim fossem, nenhuma operação intelectual que exigisse a coordenação de pensamentos seria possível de ser realizada.

Vale ressaltar que, quando analisamos a leitura e a escrita em sala de aula, estamos procurando buscar evidências que insinuem se, nesse ambiente, a criança está ou não se constituindo enquanto leitor e escritor, a partir de sua interação com o outro. E esse outro é representado não apenas pela figura do professor, como também, pelos colegas com os

Comunicações | Piracicaba | v. $24 \mid$ n. 2 | p. 215-227| maio-agosto 2017 
quais a criança interage na escola, pois é a partir da troca de conhecimentos que o indivíduo começa a se relacionar com a leitura e a escrita, em seguida com o mundo.

A palavra do outro ajuda a criança a elaborar o significado de novas palavras (VIGOTSKI, 2001), sendo que, da mesma forma que pode assumir a palavra do outro para si, pode também apresentar o sentimento da recusa, da contestação, mas mesmo assim, estará se desenvolvendo, pois sabemos que o ser humano não se constitui apenas de aceitações, mas também de negações, aprende a fazer críticas quando achar necessário, contestar quando achar algo errado; aprende a não ser um ser passivo controlado por ideias de forma acrítica, aprende a conviver nessa sociedade que exclui, marginaliza, mas também inclui, e com a ajuda do outro encontra meios para transformar essa realidade, buscando novos caminhos para a construção de sua subjetividade.

Na relação com o outro, a criança, e todos os outros indivíduos, organizam e transformam seus processos de elaboração do significado das palavras, desenvolvendo-se, constituindo assim sua humanidade no processo de intersubjetividade que ocorre no espaço escolar, mediado pelos conhecimentos sistematizados, pelos conhecimentos cotidianos, pelos afetos, pela cognição e pela emoção.

A leitura e a escrita são elaboradas pela criança nas suas relações sociais, necessitando sempre do outro como mediador nesse processo. A elaboração ativa da escrita depende principalmente das possibilidades que as crianças têm/ou não de utilizar e compartilhar essa escrita em suas interações: tudo depende do contexto sociocultural ao qual cada indivíduo está inserido. Vigotski (2000a) não considera que as relações da criança com a escrita sejam estritamente cognitivas, ou seja, não é apenas um objeto de conhecimento, mas também uma forma cultural de ação no mundo, o conhecimento da escrita utilizada pelo indivíduo para agir em sociedade.

Segundo Smolka (2001):

\begin{abstract}
A palavra materializada sobre o papel não é um fim em si mesmo. Ela cria relações entre os indivíduos: a criança aprende a ouvir, a entender o outro pela leitura, aprende a falar, a dizer o que quer pela escrita. Mas esse aprender significa fazer, usar, praticar, conhecer. Enquanto escreve, a criança aprende a escrever e aprende sobre a escrita (p. 63).
\end{abstract}

A leitura e a escrita vão além de mero conhecimento formal, sua aquisição possibilita a compreensão acerca dos fatos, das pessoas, do mundo, mas esse aprender precisa ser usado, praticado para poder ganhar sentido, valor, significado. Não se pode ensinar a escrita para a criança como algo sem importância, desprovido de significado, como uma maneira de copiar palavras, formar frases apenas, sem mostrar a sua importância e indispensavelmente sem fazer ligação com a realidade. O ensino da escrita tem privilegiado a forma e não a significação; a leitura tem se reduzido a meras pronúncias de palavras fragmentadas, vazias de conteúdos e significados e, por conseguinte, prazer e emoção.

Não é saudável ler um texto para as crianças só por ler, sem a intenção de explorar suas riquezas semânticas, polissêmicas e polifônicas, mas faz-se necessário que o profes- 
sor oportunize a troca de ideias já que cada um traz consigo sua experiência pessoal, sua história, sua ideologia, construídas socialmente em interação com outros textos em outros contextos diferenciados. A sala de aula é o lugar da prática intersubjetiva e interdiscursiva.

A leitura é importante e necessária, mas precisa ser vista como algo que venha permitir ao indivíduo concordar, discordar do que ouve ou lê, não torná-lo mero receptor passivo, alienado ao discurso do autor. Até que ponto as ideias do texto se igualam ao que meu ponto de vista enquanto ser social, e diferente, acredito e defendo? A leitura precisa proporcionar ao indivíduo não sua alienação aos fatos, às ideias, mas sim um caminho que ajude abrir novas portas para a sua construção social e cultural.

A leitura em momento algum pode ser vista pela criança como algo desnecessário, sem importância, uma obrigação, uma tarefa realizada sobre pressão, mas sim como algo necessário, mágico, que lhe possibilita nomear o mundo, como a arte do descobrimento, que abrirá caminhos para se alcançar objetivos, atingir metas, de forma dinâmica, livre, feitas de acordo com suas necessidades, ampliando a dimensão sígnica do que chega a ela, aumentando suas competências e habilidades cognitivas, afetivas etc.

Na perspectiva histórico-cultural, segundo Fontana (1997), compreender a relação das crianças com a leitura e a escrita representa a compreensão do contexto social e histórico nos quais essas crianças estão inseridas. Entender como se dá leitura e escrita na sala de aula significa compreender as relações sociais que caracterizam esse contexto e como elas contribuem/ou não para a formação de leitores e escritores.

Portanto, é necessário considerarmos os alunos reais, que habitam as salas de aula da atualidade, buscando compreender suas necessidades reais e suas capacidades emergentes.

\section{QUESTÕES NORTEADORAS:}

Profissionais da área acreditam que as dificuldades apresentadas pelos alunos na aquisição da leitura e da escrita estão diretamente ligadas às dificuldades de desenvolvimento de suas habilidades cognitivas e motoras, não se permitindo analisar como essa prática vem sendo trabalhada.

O que se está fazendo para ajudá-los nesse processo de seu desenvolvimento sociocognitivo e afetivo? A metodologia está levando em consideração os conhecimentos trazidos pelos educandos, seus conhecimentos prévios sobre leitura e escrita?

São essas perguntas que se deveria estar se fazendo no trabalho docente, procurando tornar-se um docente presente, não para dar conceitos prontos e acabados para os seus alunos, mas para servir de mediadores nessa elaboração; alguém que os ajude a descobrir a importância da leitura e escrita, e sua apropriação no ambiente social, valendo-se de estratégias teóricas e metodológicas motivadoras, que mobilizem e afetem as crianças e, ao mesmo tempo, se constitua em um desafiador caminho à aprendizagem e ao desenvolvimento de suas habilidades em leitura e escrita.

São essas questões que motivam a experimentação-pesquisa-reflexão de teoria e metodologias: diversificadas, diferenciadas, alternativas ao modelo tradicional praticado em sala de aula. Isto porque vivemos em um contexto marcado pela diversidade semiótica, de dife- 
rentes linguagens se cruzando e entrecruzando em nosso dia a dia. Um mundo de imagens diversificadas invade o cotidiano dos indivíduos. As crianças estão tendo acesso de forma sistemática e assistemática a essas imagens e a essas linguagens. O computador, o celular, a internet estão presentes no dia a dia e colocam diante dessas crianças um mundo novo de linguagens, que deve ser mobilizado a serviço de práticas motivadoras de leitura e escrita.

\section{RESULTADOS E CONSIDERAÇõES FINAIS}

Os encontros iniciavam-se, sempre, com dinâmicas sociointerativas como forma de promover a socialização entre as crianças, considerando que muitas delas estudam em turmas diferentes, como já se informou. Objetiva-se motivá-las, quebrar a inibição, provocar o contato físico, o sorriso, a alegria, por meio da ludicidade. Em seguida, discute-se as atividades a serem realizadas, sempre procurando conhecer os seus saberes prévios sobre o que se vai trabalhar, de forma a se fazer a mediação com os conhecimentos sistemáticos.

Essa estratégia de discussão tem se constituído em um importante mecanismo para envolvê-las nas atividades e, ao mesmo tempo, conhecer suas vivências e modos de elaboração conceitual das experiências de aprendizagem formal e do cotidiano extraescolar. Assim, suas narrativas, suas formas de compreensão do vivido, as expressões de suas subjetividades são tomadas como ponto de partida para o trabalho pedagógico.

Pode-se afirmar que já nos primeiros encontros observou-se uma maior assiduidade dos participantes, assim como maior interação entre eles; maior envolvimento nas atividades desenvolvidas, pois, segundo Vigotski (2000a), e sua abordagem sociointeracionista do desenvolvimento humano, é fundamental a interação com o outro mediado pelos objetos de conhecimentos para que o indivíduo possa vir a desenvolver suas habilidades cognitivas e socioafetivas.

Deve-se ressaltar que Vigotski (2000a, 2000b, 1999, 2001) apresenta elementos que reforçam sua compreensão de que o psiquismo é constituído pela interação indissociável entre afetos, emoções e intelectos, e que a vida afetiva não pode ser compreendida fora de uma dimensão sócio-histórica.

Essa perspectiva de indissociabilidade entre afetividade e cognição/intelecto é indispensável à prática pedagógica, pois os ganhos cognitivos mobilizam a dimensão socioafetiva em relação ao conhecimento e vice-versa (FALABELO, 2005).

Assim, se nos primeiros encontros percebeu-se que algumas crianças apresentavam comportamento retraído, no decorrer das atividades desenvolvidas passaram a agir de forma espontânea, ou seja, observou-se um crescendo na desenvoltura das mesmas, seja nas dinâmicas de socialização, seja na execução das tarefas de aprendizagem.

Constatou-se que numa sala heterogênea, não somente em termos de faixa etária, cada aluno é único, o aprendizado acontece de forma diferente, e isso precisa ser levado em consideração e canalizado para promover a troca de conhecimentos e experiências. Deve-se ter a sensibilidade de notar isso, buscar estratégias para que os alunos consigam se apropriar desses conhecimentos; que trabalhem em equipes; que aprendam a socializar o que sabem e 
a aprender o que não sabem; valorizar, assim, a vivência intersubjetiva entre essas crianças em diferentes situações de domínio dos conhecimentos socialmente valorizados.

Compreendendo-se que essas crianças provêm de contextos social, cultural e escolar diferenciados, que têm domínio de conteúdos diversos, procurou-se criar situações onde as mesmas se apropriem dos conhecimentos escolarizados, sempre mediados por seus saberes prévios, pelos seus conhecimentos assistemáticos, conforme já se referiu logo no início deste item. Vigotski (2000a) chama a atenção para o fato de a escola se constituir num lugar privilegiado de apropriação dos conhecimentos sistematizados, mas, ao mesmo tempo, ressalta que os saberes prévios que as crianças dominam devem ser tomados como ponto de partida ao seu desenvolvimento conceitual em sala de aula.

Faz-se, assim, necessário compreender, em conformidade com a abordagem vigotskiana, a história social das crianças e não somente sua história individual, pois como já se explicitou, na parte teórica deste artigo, a criança constitui sua subjetividade, isto é, sua individualidade, na medida em que vai se inserindo na vida social e participa das práticas culturais de seu grupo (FALABELO, 2010).

Procurou-se, não somente, valorizar acontecimentos prazerosos narrados por essas crianças, mas também situações de aprendizagem que tiveram alguma dificuldade, de forma que estas se sentissem atraídas para as atividades realizadas, visando inseri-las nas práticas letradas e na apropriação dos conhecimentos sistematizados. Privilegiou-se a escuta de seus dizeres; incentivou-se a falarem sobre o seu dia a dia; a respeito de suas dificuldades de aprendizagem; sobre o que sabiam; acerca do que desejavam aprender e fazer; sobre o que gostavam mais de estudar.

Assim, acontecimentos negativos, por exemplo, "medo" de determinado assunto programático eram tomados como tema de discussão e aprendizagem, Igualmente, temáticas que verbalizavam sentir prazer, que diziam "gostar mais" também eram exploradas e trabalhadas, buscando-se ajudar essas crianças a ressignificar sua relação com esses conteúdos. Sempre, como princípio teórico e metodológico, enfatizar, nas ações didáticas, aqueles saberes que traziam de suas comunidades e de suas vivências, por exemplo: fatos, acontecimentos, brincadeiras, gírias, histórias, "causos", e tudo que pudesse aproximar as crianças dos conhecimentos sistemáticos.

Além disso, foram trabalhadas atividades educativas diversificadas, por exemplo, cita-se: algumas palavras cruzadas, caça-palavras, pesquisa e colagem com jornais, leituras e interpretação de textos, produção de textos etc., sendo que estas eram sempre pensadas e ressignificadas de acordo com o contexto social dos alunos.

Deve-se citar, ainda, que se incentivou a prática da criança ler o que queria por meio do acesso ao "Cantinho da leitura", composta de um grande cesto com diversos e diversificados livros infanto-juvenis. Isso contribuiu para despertar o interesse maior pela leitura. A leitura livre, onde os livros e historinhas eram trabalhados de acordo com o gosto das crianças. Próximo ao "Cantinho da Leitura", alguns tapetes foram expostos, nos quais as crianças, de forma individual ou em pequenos grupos, sentadas e ou deitadas, faziam suas leituras preferidas. Tais leituras, em outro momento, eram objeto de socialização entre as crianças, com a mediação dos bolsistas. 
Acredita-se que essa estratégia, entre as outras apresentadas, despertou maior interesse e assiduidade por parte das crianças aos Encontros e ao envolvimento das mesmas com a prática da leitura e da escrita, pois aumentaram, significativamente, os empréstimos semanais de livros do "Cantinho da Leitura" para a leitura em casa.

Deve-se lembrar, ao leitor, que se está trabalhando com crianças em dificuldade no domínio da leitura e da escrita e ou repetentes em um ou mais anos; crianças que experimentaram e ainda experimentam relações negativas com as práticas escolares de alfabetização. Além do estímulo à leitura e escrita, trabalhou-se a autoestima e o comportamento das mesmas, por meio da valorização de suas pequenas conquistas, utilizando atendimento individualizado, atividades coletivas, entre crianças com níveis diferenciados de aprendizado, despertando a cultura da paz e a aceitação do outro.

Ao disponibilizar-se uma atividade extensionista contextualizada, levando as crianças a ler e a compreender o que foi lido, percebeu-se um maior empenho delas em se envolver na leitura e escrita enquanto uma prática social; à medida que iam descobrindo a função social da leitura e escrita, maior era o envolvimento das mesmas em ler e produzir seus textos, suas narrativas, de forma oral e ou escrita.

Percebeu-se, nesse rico jogo sociointerativo, que a valorização dos saberes prévios que as crianças possuem se constituem em uma importante e motivadora ferramenta para aproximá-las dos conhecimentos sistematizados e escolarizados. Ou seja, partir da realidade das crianças, tomar suas narrativas, suas histórias e as suas formas de pensar, como ferramenta pedagógica, se constituiu em diferencial para que participassem ativamente das atividades do Projeto.

Aos poucos foram realizando leituras de palavras, frases, pequenos textos e, ao mesmo tempo, passaram a produzir seus textos. Além disso, algumas dessas crianças, que de início sentiam-se receosas por suas dificuldades, não só aquelas dificuldades escolares, mas também aquelas que dizem respeito a relacionar-se com os demais, passaram a se relacionar mais, participar ativamente das atividades realizadas.

Assim, a ação didática de ouvir os seus dizeres, em suas vozes tímidas e, algumas vezes, quase inaudíveis, logo no início, cedeu lugar a crianças que passaram a falar, a expressarem com maior segurança e autonomia seus pensamentos e suas opiniões porque perceberam que havia ali um lugar de escuta; havia ali interesse pedagógico pelo que diziam. Aquele espaço passou a ser um lugar para o desenvolvimento e apropriação da leitura e da escrita, de forma significativa.

Deve-se destacar, ainda, que foi notório na realização das atividades esse avanço maior na interação entre as crianças, e assim possibilitando o trabalho em grupo com elas, já que isso não era possível, mesmo em atividades simples como montar um quebra-cabeça. Logo elas foram deixando de lado a timidez e passaram a usar mais as estratégias pedagógicas de compartilhamento dos modos de estudar e aprender em colaboração com os outros. Ou seja, passaram a valorizar a vivência intersubjetiva e interdiscursiva em seus processos de aprendizagem e formação humana.

Com emotiva alegria, percebeu-se que aquelas crianças, inicialmente muito silentes, começaram a interagir mais, demonstrando interesse nas atividades; intensificou-se a inter- 
locução tanto com os colegas quanto com os bolsistas, e não apenas verbal, mas também não verbal, por meio de olhares atenciosos e de gestos que indicavam a aceitação e satisfação na realização das atividades.

Conforme Vigotski (2000a, 2001), criança em interação diversificada com os conhecimentos, mediada pelo adulto que lhe ensina, vai se desenvolvendo, e se apropriando das práticas sociais. Diante dos trabalhos desenvolvidos no LAAL, observou-se um visível aprofundamento no interesse dessas crianças com as práticas de leitura que disponibilizamos.

No decorrer das atividades, perceberam-se, assim, mudanças significativas, tanto cognitivas - melhoria no desempenho de leitura e escrita - como comportamentais e afetiva das crianças: cooperar, competir, brincar e sorrir. E, principalmente, deve-se ressaltar a mobilização das mesmas em relação à apropriação dos conhecimentos trabalhados, por exemplo, maior interesse, atenção, concentração, empenho em realizar as atividades, esforço para ler e ou produzir um texto.

Vigotski (2000a) defende a tese de que o indivíduo se constitui nas relações sociais e, nesse sentido, suas formas de agir, pensar, sentir e atuar na realidade são aprendidas e apreendidas em suas práticas sociais e culturais, com a mediação de adultos mais experientes.

Assim, o indivíduo, para se constituir em sua humanidade, depende das possibilidades que o grupo social lhe garante, desde o nascimento, para ter acesso aos objetos culturais produzidos pela humanidade ao longo de sua história. Quanto mais ricas e diversificadas forem as situações de aprendizagens experimentadas pelo indivíduo, tanto maiores serão o progresso no desenvolvimento de suas funções psicológicas (FALABELO; LEÃO, 2014).

Apesar de ainda se ouvir, no cotidiano da sala de aula, um discurso que culpabiliza a criança e a responsabiliza por suas dificuldades em aprender a ler e escrever, às vezes atribuindo-se à questão de carência afetiva, de baixa autoestima, de problemas familiares, como já se referiu na introdução deste texto, as atividades deste Projeto Extensionista, com base na abordagem Vigotskiana, apresentam indícios importantes de que, longe de uma carência afetiva, as crianças em dificuldade de apropriação dos conteúdos escolares, precisam de condições de aprendizagens, ricas, diversificadas; necessitam de práticas que as compreendam como crianças reais, com suas histórias, com seus saberes prévios, com suas diferenças e, principalmente, com suas possibilidades de aprender e se constituir em sua humanidade.

\section{REFERÊNCIAS}

CERTEAU, M. de. A Invenção do Cotidiano: 1. Artes de fazer. Petrópolis, RJ: Vozes, 1994. FALABELO, R. N. O. A Indissociável inter-relação afetividade e cognição nos processos de leitura e escrita na Educação de Jovens e Adultos, 2005, 203s. Tese (Doutorado em Educação) - Universidade Metodista de Piracicaba, Piracicaba, SP, 2005.

FALABELO, R. N. O. Formação Humana, Docência, Afetividade e Linguagem; para além de um sujeito racional. In: OLIVEIRA, D. B.; ABREU, W. F. de; BRITO, M. dos 
R. (Orgs.). Educação em Tempos Precários: A Formação entre o humano e o inumano. Belém: GEPFEE/UFPA, 2010, p. 179-216.

FALABELO, R. N. O. Formação: Um evento intersubjetivo e interdiscursivo; enredando fragmentos. In: CHAVES, S. N.; BRITO, M. dos R. (Orgs.). Formação e Docência: Perspectivas da pesquisa narrativa e autobiográfica. Belém: CEJUP, 2011, p. 155- 203.

FALABELO, R. N. O; LEÃO, D. S. Leitura e Escrita: experiências teórico metodológicas em sala de aula. Margens, v. 6, n. 10, p. 247-273, 2014.

FONTANA, R.; CRUA, N. Psicologia e Trabalho Pedagógico. São Paulo: Atual, 1997.

PADILHA, A. M. L. Possibilidades de histórias ao contrário ou como desencaminhar o aluno da classe especial. São Paulo: Plexus, 1997.

PATTO, M. H. S. A produção do Fracasso Escolar: histórias de submissão e rebeldia. São Paulo: T. A. Queiroz, 1993.

SMOLKA, A. L. B. A Criança na fase inicial da escrita; a alfabetização como processo discursivo. São Paulo: Cortez; Campinas, SP: Ed. UNICAMP, 2001.

VIGOTSKI, L. S. A Formação Social da mente; o desenvolvimento dos processos psicológicos superiores. São Paulo: M. Fontes, 2000a.

VIGOTSKI, L. S. Pensamento e Linguagem. São Paulo: M. Fontes, 2000 b.

VIGOTSKI, L. S. A Construção do Pensamento e da linguagem. São Paulo: M. Fontes, 2001.

VIGOTSKI, L. S. AO Desenvolvimento Psicológico na Infância. São Paulo: M. Fontes, 1999.

Dados do Autor

Raimundo Nonato de Oliveira Falabelo

Doutor em Educação pela Universidade Metodista de Piracicaba. Professor do Programa de Pós-Graduação em Educação e Cultura do Campus Universitário de Cametá. Cametá/ PA - Brasil. falabelo@ufpa.br

Submetido em: 20-12-2016

Aceito em: 07-04-2017 